plasma PAF-AH activity. These alterations suggest that active RA is associated with partial loss of the antiinflammatory activity of plasma Apo B- and Apo A-I-containing lipoproteins.

\section{THU0081 AMELIORATION OF COLLAGEN INDUCED ARTHRITIS BY THROMBIN INHIBITION}

N Busso, I Marty, V Péclat, G Kirdaite, R Salvi, A So. Laboratoire de Rhumatologie, CHUV, Lausanne, Switzerland

\subsection{6/annrheumdis-2001.958}

Background The deposition of fibrin observed in arthritic joints has been proved to have a deleterious role. ${ }^{1}$

Objectives We wish to explore the effect of the thrombin inhibitor PEG-hirudin in the pathogenesis of the murine collageninduced arthritis (CIA).

Methods CIA was induced in male DBA/1J mice by intradermic injection of native chicken type II collagen. PEG-hirudin (injected subcutaneously at $1 \mathrm{mg} / \mathrm{kg}$ or $0.1 \mathrm{mg} / \mathrm{kg}$ per day) was given during 16 days, starting 20 days after the first immunisation (preventive treatment) or at the onset of clinical signs of arthritis (curative treatment).

Results All the mice treated with PEG-hirudin had a significantly prolonged thrombin time compared to control mice. PEG-hirudin, administered in a preventive way, led to significantly reduced incidence and severity of CIA during most of the treatment period, as assessed by clinical scoring. Accordingly, histological features showed a significant diminution of synovial hyperplasia in PEG-hirudin-treated mice compared to untreated mice. There was also a significant down-modulation of the synovial proinflammatory IL-1b and IL-12p35 cytokine mRNAs in treated mice. Intra-articular fibrin, evaluated by immunohistochemistry, was significantly reduced in treated mice compared to control mice and was positively correlated with both clinical and histological scorings. Most importantly, once arthritis was established, there was also a curative effect of PEG-hirudin.

Conclusion PEG-hirudin prevents the onset of CIA in a dosedependent manner and has also a curative effect on established arthritis, suggesting that thrombin inhibition may offer a new therapeutic approach in arthritis.

\section{REFERENCE}

1 Busso N, Péclat V, Van Ness K, et al. J Clin Invest. 1998;102:41-50

\section{THU0082 INDUCTION OF ADJUVANT ARTHRITIS IN THE MALE LEWIS RAT: LIPOIDAL AMINE EXHIBITS AN "ALL-OR- NOTHING" THRESHOLD RESPONSE DISTINCT FROM THE MYCOBACTERIAL LINEAR DOSE RESPONSE}

U Feige, C King, B Bolon. Pharmacology/Pathology, Amgen, Thousand Oaks, USA

\subsection{6/annrheumdis-2001.959}

Background Marked polyarthritis can be induced in male Lewis rats by injection of either heat-killed Mycobacterium tuberculosis (H37Ra, Difco) in paraffin oil (AdA) or lipoidal amine in complete Freund's adjuvant (LA/CFA).

Objectives The present study examined whether or not the disease severity in these two models is related to the dose of the inciting agent.

Methods Adjuvant arthritis was induced in male Lewis rats (190 to $240 \mathrm{~g}$ ) by administration of M. tuberculosis (AdA; 1.25, 2.5, $5,10,20$ or $40 \mathrm{mg} / \mathrm{ml}$ ) or lipoidal amine (LA/CFA; 4, 6.25,
$12.5,25,50,100,200$, or $400 \mathrm{mg} / \mathrm{ml})$. The clinical evaluation included measurements of body weight and hind paw volume (by water plethysmography) on day 0 and then daily between days 8 to 16 . At necropsy on day 16, inflammation (by histopathology) and bone integrity (bone mineral density [BMD] by DEXA; histopathology) were assessed in the tibiotarsal (hock) and femorotibial (knee) joints.

Results Induction of AdA followed a typical dose-response curve for most parameters, including body weight, loss of BMD (hock and knee), inflammation (paw volume and histopathology), and bone erosion (histopathology). In contrast, LA/CFA exhibited an "all-or-nothing" response with a threshold for activity of $50 \mathrm{mg} /$ $\mathrm{ml}$. The severity of arthritis (measured both clinically and morphologically) was comparable at day 16 for AdA engendered by $>1.25 \mathrm{mg} / \mathrm{ml}$ of mycobacteria and LA/CFA induced by $>50$ $\mathrm{mg} / \mathrm{ml}$. These data indicate that AdA and LA/CFA exhibit different dose-response patterns.

Conclusion The practical implication of this finding is that AdA will be the better adjuvant arthritis model for investigating the biology and treatment of inflammatory joint disease over a range of lesion severities.

\section{THU0083 BONE MINERAL DENSITY MEASUREMENTS ARE SUITABLE FOR RAPID QUANTIFICATION OF SKELETAL DESTRUCTION IN RATS WITH ADJUVANT ARTHRITIS}

U Feige, A Koch, B Bolon. Pharmacology/Pathology, Amgen, Thousand Oaks, USA

\subsection{6/annrheumdis-2001.960}

Background Reduced bone mineral density [BMD] is one of the major features of arthritis in both humans and animals. In a previous study, we showed that BMD was significantly decreased in both the femorotibial (knee) and tibiotarsal (ankle) joints of male Lewis rats with mycobacteria-induced adjuvant arthritis (AdA) even though clinical inflammation was most pronounced in the ankle. $^{1}$

Objectives The present experiment measured BMD in the ankles and knees of male Lewis rats with AdA to (1) define which region provides the greatest sensitivity as a rapid screen for antiarthritic efficacy and to (2) determine the progression of chronic bone loss at these sites.

Methods AdA was induced on day 0 (body weight of rats, $\sim 100$ g) by subcutaneous injection of heat-killed mycobacteria in oil; the day of AdA onset (as defined by paw swelling) was day 9 . BMD was assessed in knees and ankles on days 12, 13, 14, 15, $16,17,18,25$ or 35 (6 normal and 6 arthritic rats/day) using dual energy x-ray absorptiometry (DEXA; Model 4500A, Hologic, Waltham, MA).

Results In control rats, mean BMD for both sites increased by $20 \%$ between days 0 to 12 , remained constant between days 12 to 18 , and then increased again by $10 \%$ (ankle) or $25 \%$ (knee) by day 35. In AdA rats, hind paw volume relative to baseline values doubled between days 9 to 11 and then increased by another 1.5- to 2-fold to plateau on day 15. Mean knee BMD in AdA animals was $85 \%$ of control levels on day 12 , fell to $75 \%$ by day 15 , and ended at $55 \%$ on day 35 . In contrast, mean BMD in ankles of AdA rats was comparable to control values through day 14 , was $85 \%$ of controls on days 15 to 18 , and decreased to $60 \%$ on days 25 and 35 .

Conclusion Our data indicate that BMD loss occurs earlier and to a greater degree in the knee of rats with AdA, suggesting that 